\title{
Analysis of travel time and mode choice shift for non-work stops in commuting: case study of Beijing, China
}

\author{
Zidan Mao $^{1} \cdot$ Dick Ettema $^{1} \cdot$ Martin Dijst $^{1}$
}

Published online: 22 November 2016

(C) The Author(s) 2016. This article is published with open access at Springerlink.com

\begin{abstract}
This paper investigates travel time attributed to non-work stops in multi-purpose commuting trips. Travel time is explained by socio-demographics and spatial attributes, mode shift is also included to analyze the extra travel time, and its trade-off with activity time for four types of non-work stops-eating out, shopping, leisure/social activities, and family/personal/other. Data come from the "Daily Activity and Travel Survey of Beijing 2012". Descriptive analysis shows that almost $20 \%$ of the multi-purpose commuting trips include a mode shift toward a more motorized transport mode than their direct counterparts. Regression results indicate that extra travel time due to detours is significantly related to the activity durations. Regardless of the activity type, longer work duration reduces the travel time. Furthermore, the interaction terms between personal/trip/spatial factors and activities durations show the impacts differ across the activity types. Gender difference is found only for eating out, which suggests that male commuters travel longer for the same amount of activity time. Concerning spatial factors, a greater mix of facilities near workplaces helps to reduce the extra travel time invested for a time unit of shopping and family/personal/other activities. Compared with public transit users, active mode users have shorter travel time for eating out. Timing, work duration and commuting duration as time-budget-related variables show negative impacts on the extra travel time for eatingout, shopping and family/personal/other activities. However, mode shift does not show any significant impact as the hypothesis proposed. Instead of rebalancing the trade-off between travel and activity time, commuters may relocate activity with an expanded opportunity choice set given by a higher mobility level.
\end{abstract}

Zidan Mao

Z.Mao@uu.nl

Dick Ettema

D.F.Ettema@uu.nl

Martin Dijst

M.J.Dijst@uu.nl

1 Department of Human Geography and Spatial Planning, Faculty of Geosciences, Utrecht University, 3508 TC Utrecht, The Netherlands 
Keywords Commuting · Non-work stops · Travel time - Mode shift - Travel time price Beijing

\section{Introduction}

Commuting behavior has been an important topic in transportation research for decades (Cervero and Wu 1998; Horner 2004; McGuckin and Murakami 1999; Sultana and Weber 2014). In addition to direct commute trips, extra stops added to the commute journey have recently received increased attention (Bhat 1999; Bhat and Sardesai 2006; Cao et al. 2008; Currie and Delbosc 2011; Ma et al. 2014; McGuckin et al. 2005; Portoghese et al. 2011; Susilo and Kitamura 2008; Van Acker and Witlox 2011). The increasing presence of dualearner households and the growing acceptance of sharing household tasks between spouses (Levinson and Kumar 1995; Soo et al. 2008) increase time pressure for urban families and consequently encourage trip-chaining behavior. For example, a household travel survey in metropolitan Washington, DC showed that multi-purpose commute trips increased from 1.5 to $15 \%$ between 1968 and 1988 (Levinson and Kumar 1995). This trend was confirmed on a national scale for the USA from 1995 to 2001, with a $9 \%$ increase in commuters who chained trips as part of their commutes (McGuckin et al. 2005). For individuals, trip chaining behavior may provide greater efficiency and convenience in their daily lives (Hensher and Reyes 2000; Ye et al. 2007), and for households, frequent multi-purpose commute trips play a major organizational role in their overall travel patterns (Hanson 1980). However, for urban transportation systems, the substantial increase in non-work stops in commuting may result in severe problems; for example, pressure in peak hours can increase because of the extra travel time for the stops (Bhat 1997).

Although previous studies have addressed many aspects of commute trip chains, such as occurrence (Cao et al. 2008; Nishii and Kondo 1992), stop frequency (Bhat 1997; Portoghese et al. 2011), stop duration (Bhat 1996a, b; Brunow and Gründer 2013), tour scheduling (Islam and Habib 2012; Ma et al. 2014) and location choice (Wang et al. 2013), the impacts of trip chaining on travel time have received little attention. Trip chaining in the context of commuting implies detours and extra travel time, the amount of which is likely to depend on the salience and duration of the secondary activity, geographical locations of the activity sites and increase in the efficiency of daily activity schedules. Soo et al. (2008) and Susilo and Dijst $(2009,2010)$ developed an analytical model to relate extra travel time (as compared with direct commute trips) to the duration of the secondary activity, expressed in the so-called travel time ratio (TTR). They found that the value of the TTR is affected by the journey types (to work or from work), trip purposes, socio-demographics of the travelers and built-environment opportunities. However, travel mode choices were assumed to be the same for direct trips and trip chains in their studies. In this paper, we argue that commute trip chains may in fact be the results of more complex behavioral adjustments, in which commuters may not only decide to include secondary destinations in their commute trips but also change the travel modes or timing of the commute trips. These strategies may have a considerable bearing on the extra travel time needed for trip chaining. Neglecting these strategies may lead to wrong conclusions regarding daily time use and travel times and consequently the sustainability and wellbeing implications. The aim of this paper is to investigate travel time attributed to nonwork stops in commuting and examine the possible factors that affect the extra travel time 
and its trade-off with activity time in multi-purpose commute trips in Beijing, China. A series of socio-demographic and spatial attributes (at the residence and workplace) will be included. Specifically, one aspect of our research is to explore the influence of transport mode shift on extra travel time. The availability of multi-day travel and activity data in Beijing allows us to make these detailed comparisons between direct and multi-purpose commute trips at the individual level.

The study area for this research is Beijing, China. Empirical studies on trip chaining behavior have largely focused on European or American cities. With rapid urbanization occurring in China, traffic congestion and accessibility deficiencies have become primary challenges (Chai 2013). As for transport mode choices in Chinese cities, public transit dominates, whereas urban residents have become increasingly dependent on automobiles. In Beijing, trips by public transit accounted for $44.0 \%$ of all the trips (trips on foot excluded) by the residents in 2012, whereas trips by private car accounted for $32.6 \%$. Specifically, private car ownership increased sharply from 1.8 to 4.2 million between 2005 and 2012 (Beijing Transport Research Center 2013). A deeper understanding of trip chaining behavior with this state of transport mode choices will enrich the travel behavior research and may contribute to better policy making in the context of developing economies (Ma et al. 2014; Yang et al. 2007).

The rest of this paper is organized as follows. The next section presents a brief review of previous studies on the trade-off between travel and activity time and the formulation for travel time attributed to non-work stops in this study. "Data" section introduces the data source, dataset preparation, and method for the analysis. The model estimation results are discussed in "Results" section. The conclusion and discussion are presented in the final section.

\section{Travel time for non-work stops in multi-purpose trips}

Previous studies have identified the influential factors on travel time for non-work activities. Personal and household attributes such as gender, age, income, household (worker) member numbers have been found to influence travel time (Golob et al. 1995; Schwanen et al. 2002; Tarigan et al. 2012). Regarding trip attributes, while shopping travel time decreases as their accessibility to vehicles increases in Canadian cities (Farber et al. 2011), in Dutch cities that discourage car use, drivers takes a relatively long time (Schwanen et al. 2002), Among the built environment factors, residential context has especially been examined (Schwanen et al. 2002; Cao et al. 2009).

Another factor influencing travel time is the duration of the activity at the destination. With respect to the direct relation between activity and travel time, some studies show that travel time increases with activity duration (Kitamura 2002; Kitamura et al. 1998; Levinson and Kumar 1995). However, individuals' activity-travel behavior in urban space is constrained to the inseparability and scarcity of space and time (Dijst 1999; Hägerstrand 1970; Kondo and Kitamura 1987; Neutens et al. 2011). In other words, there is a trade-off between travel and activity time given the limited time budget of each individual (Dijst and Vidakovic 2000). TTR developed by Dijst and Vidakovic (2000) and the travel time price (TTP) by Chen and Mokhtarian (2006) are defined to to investigate this trade-off between travel time and activity time. TTR is defined as a ratio of travel time allocated to the total amount of travel time and activity time, whereas TTP is a ratio of travel time allocated to 
activity time, and the two concepts can be converted as TTP $=$ TTR/ $1-$ TTR. The formulation for TTP can be transferred as (Eq. 1):

$$
\mathrm{T}_{\mathrm{j}}=\varphi_{\mathrm{j}} \mathrm{D}_{\mathrm{j}}
$$

In this expression, $\mathrm{T} \mathrm{j}$ is the total travel time used for activity $\mathrm{j}, D_{j}$ is the duration of activity type $j$ and $\varphi_{j}$ is the TTP value.

This trade-off relation differs across different activity types, and this has been explored in various empirical studies. Dijst and Vidakovic (2000) first applied the TTR concept to non-work activities for a small sample of dual-earner families, and found that the ratio for maintenance activities ranged between 40 and 50\% versus 20 to $30 \%$ for discretionary activities. Then, the travel time ratio for work activities was discussed and calculated to be $10.5 \%$ based on data from the 1998 Dutch National Travel Survey (Schwanen and Dijst 2002). Chen and Mokhtarian (2006) compared not only the TTP values for maintenance and discretionary activities but also their elasticity. Their findings indicated that travel time spent on maintenance activities was less elastic than that spent on discretionary activities.

With the exception of Dijst and Vidakovic (2000), the studies noted above examine the trade-off in single-purpose trips. Because trip chaining is now a common practice in our daily lives, the TTR and TTP concepts have been extended to explore the trade-off of activities in multi-purpose trips. Susilo and Dijst $(2009,2010)$ calculated TTR values for both mandatory and discretionary activities for multi-purpose trips. They first computed the travel time related to the secondary activity by deducting "the travel time needed for a direct trip between bases" from the "actual total travel time". In the case of commute trips with more than one additional activity location, their solution was to distribute the TTR value based on the weighted durations of the activities. They employed multilevel regression models to explore the determinants of TTR on journey episode, individual, household and environmental levels. Their results show the efficiency of multi-purpose trips, as the number of activities chained has a negative influence on TTR. Soo et al. (2008) provided a more general approach for the TTP for multi-purpose trips, in which time spent in each activity contributes independently to the total travel time in the trip. Importantly, the impact of activity duration on travel time may in their formulation depend on sociodemographic or contextual factor, which is represented by interaction terms.

Our purpose here is to examine the trade-off between travel and activity time for secondary activities when adding non-work stops to commuting, therefore, we focus on the extra travel time added to commuting trips. The travel time attributed to non-work stops ( $\left.\mathrm{T}_{\text {non-work }}\right)$ is computed by deducting the travel time for the direct commute trip $\left(\mathrm{T}_{\text {direct }}\right)$ from the total travel time for multi-purpose commute trips $\left(\mathrm{T}_{\text {total }}\right)$. As mentioned above, compared to travel time calculated on road network, actual travel time can be affected by more complicated traffic conditions (e.g. congestions) and also individuals' choices (e.g. departure in the rush hour, switching to a different travel mode). When using actual travel time recorded for direct and indirect trips in practice, it is possible for this additional travel time to be negative values. We assume that $T_{\text {non-work }}$ is related to the duration of the nonwork stops as follows:

$$
T_{\text {non-work }}=T_{\text {total }}-T_{\text {direct }}=\alpha_{i} X_{i}+\sum_{j \in C} \beta_{j} D_{j}+\sum_{i} \gamma_{j i} X_{i} D_{j}
$$

In this expression, $D_{j}$ is the duration of activity type $j, C$ is the choice set for activity types, and the variable $X_{i}$ represents personal, trip and spatial characteristics. As travel time could be affected by the personal and household, trip and spatial attributes (e.g. Schwanen 
et al. 2002; Cao et al. 2009; Tarigan et al. 2012), this direct impact could also apply to the extra travel time in multi-purpose trips, and the direct impacts of these attributes $\left(X_{i}\right)$ will be estimated in our analysis. In line with the TTR/TTP literature, we assume also that extra travel time may be influenced by the duration of the secondary activity of type $\mathrm{j}\left(D_{j}\right)$. Finally, we assume, in line with Soo et al. (2008) that the effect of duration $\left(D_{j}\right)$ may be modified by personal, household or spatial attributes (Xi), expressed in the interaction term $X_{i} * D_{j}$. Because for each multi-purpose commute trip we know the duration of the nonwork stops $D_{j}$, the model can be estimated as a regression model with $X_{i}, D_{j}$ and the interaction $X_{i} D_{j}$ as explanatory variables. By including explanatory variables related to the recorded actual trips (i.e., timing, modal shift), this model structure is flexible to analyze $\mathrm{T}_{\text {non-work }}$ values whether they positive or negative.

Our model has some specific innovative characteristics. In previous studies concerning the trade-off between travel and activity time, spatial variables discussed include the density of inhabitants (Schwanen and Dijst 2002; Soo et al. 2008), density of retail or service facilities (Soo et al. 2008; Susilo and Dijst 2009), and location or urbanization level (Schwanen and Dijst 2002; Susilo and Dijst 2009). These studies show that spatial variation may offer a better explanation than socio-demographic variables for the TTR value of work activities; for example, higher density and residing in suburbs tend to result in a higher TTR. However, only spatial attributes in the vicinity of the place of residence have been included. Although Schwanen and Dijst (2002)'s descriptive analysis confirmed that TTR varies with the location of the workplace, this indicator has not been included in multivariable analyses. Because commute trips are anchored by two bases rather than the place of residence, the spatial attributes in this study will include both the anchors.

Another important addition to previous studies here is allowing for mode shifts between the direct trips and the trip chaining behavior. Thus far, mode choice has been regarded as an invariant decision in studies concerning the relation between mode choice and trip chaining behavior (Strathman et al. 1994; Walle and Steenberghen 2006; Ye et al. 2007). This is because their data are mostly based on one-day observation rather than multi-day, and the difference in mode choice has been explored mostly from an inter-personal rather than an intra-personal perspective. A few studies have shed light on the intra-personal variation of trip chaining behavior, such as Bhat (1999), in which the unobserved heterogeneity for non-work stop-making in evening commuting with multi-day data were accommodated. Despite the reorganization of the day-to-day variation of stop-making in this study, the work-related explanatory variables (work duration, departure time, travel time for direct trip, mode choice) were still regarded as pre-determined. Moreover, a very high fraction of individuals in their sample used the car mode and had little penetration for other modes; consequently, the mode choice showed no significant impact on the variation of stop-making. However, given their desired activities and time-space opportunities, some population categories have choice opportunities for their travel behavior (Dijst et al. 2002) or may need to negotiate the allocation of vehicles on a day-to-day basis. As a result, there is an opportunity to use different travel modes for a direct trip and a multi-purpose trip, which may significantly impact the TTP as expressed in Eq. (2). For example, by shifting from a slower (e.g., bicycle) to a faster mode (e.g., car), one may be able to minimize extra travel time to conduct the secondary activity or even save time compared with the direct trip. Additionally, by shifting (part of) the multi-purpose trip in time, travel time might be reduced. For example, by engaging in a secondary activity after work, the trip from the secondary activity site to the place of residence may be postponed until after the peak period, leading to an overall shorter travel time. Therefore, this paper aims to 
include these strategies into the analysis of the travel time invested in non-work stops in commuting to obtain greater insight into the trade-offs and outcomes of trip chaining behavior in such a rapidly developing city as Beijing.

\section{Data}

The data come from the "Daily Activity and Travel Survey of Beijing 2012". Since public transport dominates in the city of Beijing, on the one hand, the lack of flexible transport modes (i.e. private car) may make against the complex tour making behavior of residents (Yang et al. 2007). On the other hand, the traditionally high density, mixed land use pattern due to the heritage of Work-unit (Danwei) can encourage complex tour patterns. For example, Ma et al. (2014)'s study in Beijing found that higher density in residential neighborhood leads to more home-based tours with fewer stops, while mixed land use at workplace with higher density and accessibility leads to more stops within one work tour or a more complex tour pattern.

This survey was conducted from October to December 2012 in the Shangdi-Qinghe area, which is located northeast of Beijing's 5th ring road. This suburban area serves as a residential center, with 240,000 residents, and also as a job sub-center, with more than 5000 companies and 160,000 jobs (Fig. 1). The survey first collected the socio-demographic characteristics of the respondents and then activity diaries filled out by the respondents for one week and GPS data from GPS loggers carried by the respondents. The complete dataset contains responses from 709 respondents. Based on the research aim, the sample for the current analysis comprises 275 multi-purpose commute trips conducted by 178 commuters, who reported both direct and multi-purpose commute trips in the diaries. Sixty-five commuters contributed more than one multi-purpose commute trip; thus, the

Fig. 1 Research field location

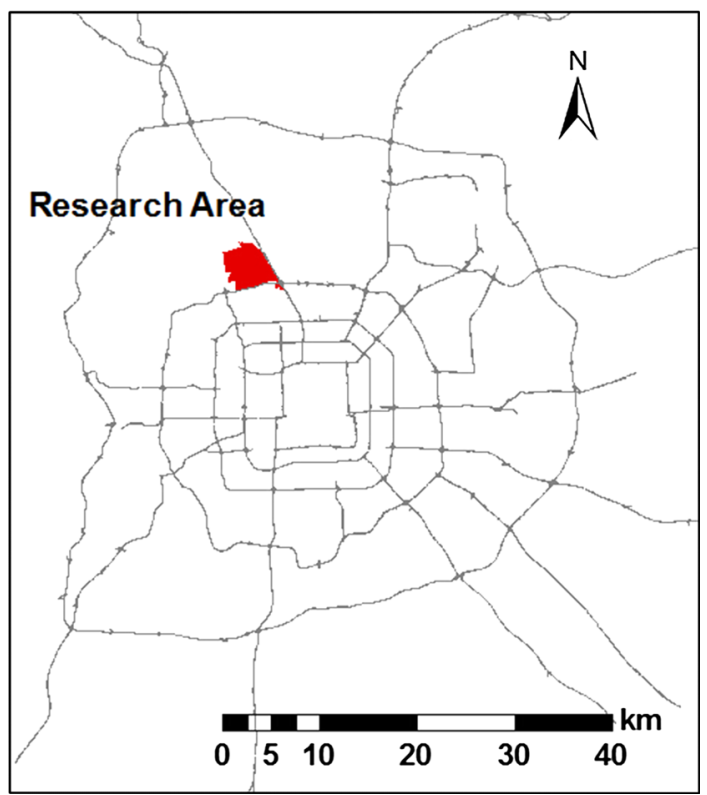


number of multi-purpose trips is larger than the number of commuters and is not evenly distributed among the commuters.

Table 1 provides a list of the explanatory variables used in the regression model, their definitions, and associated descriptive statistics. For these non-work stops in multi-purpose commuting trips, we distinguished 4 types of secondary activities of the commuters including eating out, shopping, recreation/social activities, and family/personal/other activities as secondary activities. Of the multi-purpose trips, $52.9 \%$ are combined with eating out activity, $28.6 \%$ with leisure or social activity, $20.3 \%$ with shopping activity and $14.1 \%$ with family/personal/other activity. $15.6 \%$ of the trips (43 cases) have included stops for more than one activity types. Furthermore, the duration for each activity has been extracted from travelers' activity dairies. Particularly, the standard deviation for family/ personal and other activities is large at $62.7 \mathrm{~min}$, which is likely related to its diversity

Table 1 Variables in regression for travel time attributed to non-work stops

\begin{tabular}{|c|c|c|c|c|}
\hline Variable & Definition & Distribution & Mean & SD \\
\hline \multicolumn{5}{|c|}{ Non-work stop activity duration (zero-observations excluded) } \\
\hline $\begin{array}{l}\text { Eating out } \\
\text { duration }\end{array}$ & Duration of eating out activity in non-work stops (min) & - & 68.0 & 59.4 \\
\hline $\begin{array}{l}\text { Shopping } \\
\text { duration }\end{array}$ & Duration of shopping activity in non-work stops (min) & - & 47.1 & 48.1 \\
\hline $\begin{array}{l}\text { Leisure/social } \\
\text { duration }\end{array}$ & $\begin{array}{l}\text { Duration of leisure/social activities in non-work stops } \\
(\min )\end{array}$ & - & 127.4 & 68.2 \\
\hline $\begin{array}{l}\text { Family/personal/ } \\
\text { other duration }\end{array}$ & $\begin{array}{l}\text { Duration of family/personal/other affairs in non-work } \\
\text { stops (min) }\end{array}$ & - & 53.5 & 62.7 \\
\hline \multicolumn{5}{|c|}{ Socio-demographic and trip-related attributes } \\
\hline Gender & $\begin{array}{l}1 \text { if the individual is male (female as the reference } \\
\text { category) }\end{array}$ & $42.5 \%$ & - & - \\
\hline $\begin{array}{l}\text { Extended } \\
\text { household }\end{array}$ & 1 if the commuter lives in an extended household & $12.0 \%$ & - & - \\
\hline Timing & 1 if the trip is a work-home trip & $78.2 \%$ & - & - \\
\hline Active mode & $\begin{array}{l}1 \text { if the main transport mode is active (foot or bicycle), } \\
\text { public transit as the reference category }\end{array}$ & $13.8 \%$ & - & - \\
\hline Car & $\begin{array}{l}1 \text { if the main transport mode is car, public transit as the } \\
\text { reference category }\end{array}$ & $43.3 \%$ & - & - \\
\hline Mode shift & $\begin{array}{l}1 \text { if the mode is more motorized than that for direct } \\
\text { trips }\end{array}$ & $19.3 \%$ & - & - \\
\hline $\begin{array}{l}\text { Commuting } \\
\text { duration }\end{array}$ & Duration of average direct commute (min) & & 48.3 & 24.8 \\
\hline \multicolumn{5}{|l|}{ Spatial factors } \\
\hline $\begin{array}{l}\text { Workplace } \\
\text { density }\end{array}$ & Facility density within $1 \mathrm{~km}$ of workplace of individual & - & 315.4 & 170.0 \\
\hline Workplace mix & $\begin{array}{l}\text { Facility diversity within } 1 \mathrm{~km} \text { of workplace of } \\
\text { individual }\end{array}$ & - & 0.3 & 0.0 \\
\hline Home density & Facility density within $1 \mathrm{~km}$ of home of individual & - & 244.7 & 141.4 \\
\hline Home mix & Facility diversity within $1 \mathrm{~km}$ of home of individual & - & 0.4 & 0.0 \\
\hline
\end{tabular}

- Not applicable 
because it includes family activities, such as picking up or dropping off family members, and personal affairs, such as seeing doctors and visiting hairdressers.

Of the multiple-purpose commute trips, $78.0 \%$ (215) are trips from work and the other 60 trips are to work. The mode share in the sample is as follows: $43.3 \%$ car, $42.9 \%$ public transit and $13.8 \%$ active modes (i.e., foot and bicycle). For all the commuting trips in the complete dataset, the largest proportion belongs to public transit trips $(51.0 \%)$, and the proportion for car trips is much lower at only $21.8 \%$. The difference in mode shares is consistent with the previous finding that multi-purpose trips are more car-oriented (Bhat 1997; Islam and Habib 2012).

Commute duration (for direct commute) as a constraint-related variable was subtracted from the diary data reported. For those commuters who had reported more than one direct commute trip, the value was computed by averaging the trip durations with the most frequently used mode. As for spatial factors, Points of Interest (POIs) data in Beijing were used to assess the density and mix level in $1 \mathrm{~km}$ around the two bases. In this paper, POIs density stands for the density level, and the mix level is indicated by the diversity of POIs as shown in Eq. (3) (Frank et al. 2004; Long and Liu 2013):

$$
M=-\sum_{i=1}^{n} p_{i} \times \log \left(p_{i}\right)
$$

In the equation, $p_{i}$ is the proportion of the POIs of type I; $n$ denotes the number of POI types under consideration. The POI types $(n=4)$ here include commercial, public service, public recreation, and transport facilities.

\section{Results}

This section presents an overview of the results. In the first section, we present the descriptive results of the extra travel times for different types of trips. In the second section, we discuss how extra travel time is affected by activity time, the spatial settings around the residence and workplace, socio-demographics, and strategies such as travel mode switching. To this end, a regression model according to Eq. (2) was estimated with the data outlined above.

\section{Travel time attributed to non-work stops}

To compute the travel time for non-work stops, the total travel time for multi-purpose trips $\left(\mathrm{T}_{\text {total }}\right)$ and the direct travel time $\left(\mathrm{T}_{\text {direct }}\right)$ have been subtracted from the multi-day diary for each commuter. $T_{\text {total }}$ is the travel time spent on that multi-purpose trip as reported, while $\mathrm{T}_{\text {direct }}$ for its direct counterpart is based on the travel time for same trip type (i.e. journey to and from work) reported in other days. With multiple observations, $\mathrm{T}_{\text {direct }}$ is the average value of direct commute durations with their most frequently used transport mode. As Table 2 shows, the average $\mathrm{T}_{\text {total }}$ is $76.8 \mathrm{~min}$, and the average travel time attributed to nonwork stops $\left(\mathrm{T}_{\text {non-work }}\right)$ is $28.5 \mathrm{~min}$. With an average activity duration of $89.6 \mathrm{~min}$, the general TTP value for chained non-work stops is 0.3 . It is lower than the value of 0.4 revealed in Susilo and Dijst (2010) (the original TTR value for two-base journeys in their findings has been converted to the TTP value here), which may suggest a high efficiency of trip chaining behavior in Chinese cities. 
Table 2 Calculation of travel times for trips with different secondary activities

\begin{tabular}{|c|c|c|c|c|c|c|c|c|c|c|}
\hline & \multicolumn{2}{|c|}{ Eating out } & \multicolumn{2}{|c|}{ Shopping } & \multicolumn{2}{|c|}{$\begin{array}{l}\text { Leisure/social } \\
\text { activity }\end{array}$} & \multicolumn{2}{|c|}{$\begin{array}{l}\text { Family/personal/ } \\
\text { other activity }\end{array}$} & \multicolumn{2}{|c|}{$\begin{array}{l}\text { All non-work } \\
\text { activities }\end{array}$} \\
\hline & $\begin{array}{l}\text { Mean } \\
(\mathrm{min})\end{array}$ & $\begin{array}{l}\text { Std. } \\
(\mathrm{min})\end{array}$ & $\begin{array}{l}\text { Mean } \\
(\mathrm{min})\end{array}$ & $\begin{array}{l}\text { Std. } \\
(\mathrm{min})\end{array}$ & $\begin{array}{l}\text { Mean } \\
(\mathrm{min})\end{array}$ & $\begin{array}{l}\text { Std. } \\
(\mathrm{min})\end{array}$ & $\begin{array}{l}\text { Mean } \\
(\mathrm{min})\end{array}$ & $\begin{array}{l}\text { Std. } \\
(\mathrm{min})\end{array}$ & $\begin{array}{l}\text { Mean } \\
(\mathrm{min})\end{array}$ & $\begin{array}{l}\text { Std. } \\
(\mathrm{min})\end{array}$ \\
\hline $\mathrm{T}_{\text {total }}$ & 72.5 & 35.8 & 71.1 & 39.3 & 85.5 & 48.0 & 83.6 & 31.6 & 76.8 & 39.8 \\
\hline $\mathrm{T}_{\text {direct }}$ & 51.9 & 22.7 & 44.1 & 23.0 & 45.3 & 27.1 & 47.4 & 28.8 & 48.3 & 24.8 \\
\hline$T_{\text {non-work }}$ & 20.6 & 33.2 & 27.0 & 33.9 & 40.2 & 36.5 & 36.2 & 33.4 & 28.5 & 35.1 \\
\hline
\end{tabular}

Based on the travel times reported, there are 40 negative values for $\mathrm{T}_{\text {non-work}}$. These negative values suggest that adding non-work stops does not necessarily increase the commute duration but may lead to a reduction in travel time. A detailed inspection of these cases reveals that the reasons include personal strategies for multi-purpose trips, such as mode shift (9 cases), departure adjustment (12 cases with departure times more than 30 min earlier or later than direct trips) and a longer direct travel time reported due to traffic or out-of-vehicle waiting time.

As for the average $T_{\text {non-work }}$ for multi-purpose commute trips with different secondary activity types (for multiple activities chained, the one with the longest duration is identified as the secondary activity in this calculation), trips with leisure/social activity have the longest duration of $40.2 \mathrm{~min}$. Trips with eating out have the shortest $\mathrm{T}_{\text {non-work }}$, at $20.6 \mathrm{~min}$, and the longest $\mathrm{T}_{\text {direct }}$ of $51.9 \mathrm{~min}$. Family/personal/other activities are also travel-time-consuming, especially with their shorter average duration taken into consideration. Shopping activity has the shortest activity duration as shown in Table 2, and trips with shopping as secondary activity also have the shortest duration for $\mathrm{T}_{\text {direct }}$ and $\mathrm{T}_{\text {non-work}}$. Because $15.6 \%$ (43 cases) of the trips chained more than one non-work activity as part of the commutes, the TTP value for each activity type chained must be examined in the regression model.

According to the simple regression model with the interactions between activity duration and activity type as the only explanatory variables (Model 1 in Table 3), the TTP values for different activity types can be identified. Generally, family/personal/other activities have a higher TTP value than others. This is presumably because some categories of these activities, such as picking up or dropping off a family member, do not require much activity time but may have a specific location requirement. Leisure/social activities have a relatively lower TTP value, which is related to the longer duration of these types of activities. Shopping activity has a similar TTP value to leisure/social activities. From the literature (Susilo and Dijst 2010) we know that differences exist between different types of shopping activities; for example, grocery shopping is characterized by a higher TTR than non-daily shopping. However, in our dataset, we are not able to distinguish between these shopping categories. The TTP value for eating out activity is the lowest and not statistically significant, which implies that there is no systematic relationship between activity duration and detour time. Thus, TTP would not be a meaningful concept in the context of eating out as a secondary activity. One possible explanation is that eating out as a maintenance activity is geographically highly clustered around the bases. Additionally, the activity duration of eating out may vary more than for other activity types. Despite the different classification of activity types, the TTP values in this paper are generally lower than those for discretionary and other activities in the one-base multi-purpose trips in Soo et al. (2008). This is because only the additional travel time is attributed to activity duration, rather than the total travel time. 
Table 3 Regression results for travel time attributed to non-work stops

\begin{tabular}{|c|c|c|c|c|}
\hline & \multicolumn{2}{|c|}{$\begin{array}{l}\text { Model } 1 \text { ( } 275 \text { trips, } \\
177 \text { individuals) }\end{array}$} & \multicolumn{2}{|c|}{$\begin{array}{l}\text { Model } 2 \text { (266 trips, } \\
171 \text { commuters) }\end{array}$} \\
\hline & Coefficient & t-Stat. & Coefficient & t-Stat. \\
\hline \multicolumn{5}{|l|}{ Activity durations } \\
\hline Eating out duration & 0.051 & 1.290 & $0.50^{\mathrm{b}}$ & 2.57 \\
\hline Shopping duration & $0.152^{\mathrm{b}}$ & 2.129 & $2.98^{\mathrm{a}}$ & 3.13 \\
\hline Leisure/social duration & $0.138^{\mathrm{a}}$ & 4.419 & $0.14^{\mathrm{a}}$ & 3.35 \\
\hline Family/personal/other duration & $0.224^{\mathrm{a}}$ & 3.207 & $1.89^{\mathrm{a}}$ & 3.34 \\
\hline \multicolumn{5}{|l|}{ Personal/trip/environmental attributes } \\
\hline Gender (ref. $=$ female) & - & - & - & - \\
\hline Extended household & - & - & - & - \\
\hline Work duration & - & - & $-0.04^{\mathrm{b}}$ & -2.10 \\
\hline Timing (ref. $=$ home-to-work trip) & - & - & - & - \\
\hline Active mode (ref. $=$ public transport) & - & - & -15.02 & -1.96 \\
\hline Car & - & - & - & - \\
\hline Mode shift & - & - & - & - \\
\hline Direct commute duration & - & - & - & - \\
\hline Workplace density & - & - & - & - \\
\hline Workplace mix & - & - & - & - \\
\hline Home density & - & - & - & - \\
\hline Home mix & - & - & - & - \\
\hline \multicolumn{5}{|l|}{ Interaction terms } \\
\hline Eating out duration*gender & - & - & $0.30^{\mathrm{a}}$ & 3.94 \\
\hline Eating out duration*work duration & - & - & -0.00 & -1.75 \\
\hline Eating out duration*active mode & - & - & -0.24 & -1.82 \\
\hline Eating out duration*direct commute duration & - & - & $-0.01^{\mathrm{a}}$ & -3.69 \\
\hline Shopping duration*timing & - & - & $-0.64^{\mathrm{b}}$ & -2.47 \\
\hline Shopping duration*direct commute duration & - & - & $-0.01^{\mathrm{b}}$ & -2.20 \\
\hline Shopping duration*workplace mix & - & - & $-5.75^{\mathrm{a}}$ & -2.60 \\
\hline Social/leisure duration*Car & - & - & -0.10 & -1.67 \\
\hline Family/personal/other duration*timing & - & - & $-0.35^{\mathrm{a}}$ & -2.69 \\
\hline Family/personal/other duration*direct commute duration & - & - & $-0.01^{\mathrm{a}}$ & -3.40 \\
\hline Family/personal/other duration*workplace mix & - & - & $-2.77^{\mathrm{b}}$ & -2.04 \\
\hline $\mathrm{R}^{2}$ & 0.098 & & 0.339 & \\
\hline Sig. & 0.000 & & 0.000 & \\
\hline
\end{tabular}

\footnotetext{
* Multiplication required by Eq. (2)

${ }^{\text {a }}$ Coefficients that are significant at $1 \%$ level

b Coefficients that are significant at $5 \%$ level
}

\section{Effects of travel, socioeconomic and spatial factors on extra travel time}

With other explanatory variables included, Table 3 presents an extended regression model (Model 2) considering socio-demographic attributes, spatial factors, trip attributes and their interaction with activity duration. Due to missing values for the spatial attributes ( 6 trips by 
6 individuals), Model 2 includes 266 trips travelled by 171 commuters. Several other socio-demographic variables, such as age, monthly income were included but did not significantly impact the travel time for any activity type. The interaction terms are retained in the model when they are significant at the $10 \%$ level.

Generally, activity durations still significantly and positively affect travel time after controlling all the other explanatory variables. As for the personal/trip/environmental attributes, regardless of the activity types and durations, longer work duration reduces the time budget for travelling and shows a significantly negative impact. In this Chinese context, the other household members (e.g. retired parents) in an extended household were expected to alleviate the time constraints for out-of-home activities, which may influence time allocation to travel. Descriptive analysis reveals that commuters from extended households significantly travel longer (46.7 $\mathrm{min}$ ) than the other commuters (32.6 $\mathrm{min})$. However, it shows no significant influence in the regression model after controlling other explanatory variables. Active mode commuters may also travel shorter time than public transport users to non-work stops, although only significant at the $10 \%$ level. This could be because that active mode users locate their destinations closer to their commute routes.

Consistent with the hypothesis proposed in the second section, some population categories have the option to adapt their transport modes to their desired activities and activitytravel agendas. To examine its influence, mode shift is defined as a dummy variable whether the mode adopted for this multi-purpose trip is more motorized than its direct counterpart. According to our observations, 52 multi-purpose commute trips (19.3\%) were identified with mode shifts. Compared with the direct counterparts, 42 of them switched to cars (29 from public transit, 13 from active modes) and 10 switched to public transit from active modes. However, there were also 4 individuals who used public transit for multipurpose commuting trips but cars for direct trips. They likely took this action due to Beijing's traffic restriction policy, which forbids cars to enter the 5th ring road from $7 \mathrm{am}$ to $8 \mathrm{pm}$ on one specific workday according to the last digit on their car plates. However, the variable of mode shift shows no significance across all the activity types. Switching to a more motorized transport mode does not significantly change the trade-off between travel and activity time for non-work stops. This finding contradicts our hypothesis that a mode shift would increase the travel speed and thereby reduce the extra travel time. A possible explanation is that commuters relocate activities when they get access to a car. As a larger travel speeds increases commuters' space-time prisms (Chen and Kwan 2012; Dijst et al. 2002; Nishii and Kondo 1992; Walle and Steenberghen 2006) individuals may locate their non-work stops farther from the bases.

Although only two attributes are found to directly affect the extra travel time, a further examination of the interaction terms reveals that the impacts of these explanatory variables differ across various activity types. For the socio-demographic attributes, we found that male commuters are inclined to travel longer for each time unit of an eating out activity stop during their commutes. This may be because that eating out can be different as a socializing (relation-building) activity or a maintenance activity for different genders. For male commuters, many eating out activities are likely to be a social eating for the development of workplace relationships, while due to entailing male activities or intruding on home and family responsibilities, women are less likely to be involved in these activities in a Chinese context (Bedford 2015). For these situations, the male commuters may have to socialize with colleagues and also clients/customers, other people external to their organizations located dispersedly, in which they may have less freedom in choosing the locations. Then, they have to travel to farther locations for a specific eating out activity 
and result in a higher TTP for eating out activity. However, gender-based differences have not been found in other activity types.

Transport mode choice significantly impacts the extra travel time for eating out and leisure/social activities. Given the same amount of activity time, commuters who use active modes spend less time traveling for eating out than public transit users. This finding indicates that active mode commuters choose the activity locations with shorter distances from the bases or commuting routines because the speed of the active mode is apparently lower. For leisure/social activities, although only significant at the $10 \%$ level, car users spend significantly less travel time per time unit of the activity. As a more motorized mode with higher speed and more flexibility, the car could help commuters reduce their travel time for the same amount of leisure/social activities duration.

As for the influences of other trip-related variables, longer commute duration encourages shorter travel time for eating, shopping and family/personal/other activities. It has been found that longer travel time to work results in tighter time constraints and consequently appears to reduce the number of stops made by individuals (Bhat 1997). Similarly, having a longer direct commute also reduces the travel time spent for the stops within the limited time window.

Additionally, the majority of multi-purpose commuting trips (78.0\%) are journeys from work. This finding is highly related to the time window available to commuters. Typically, morning commuting may have a smaller time window, whereas evening commuting may provide larger potential action space (Susilo and Dijst 2010). In the extended regression model in Table 3, having non-work stops in work-to-home journeys shows a negative effect on shopping and family/personal/other activities. In other words, people travel shorter for each time unit for these activities, when they are conducted after work. This may be caused by longer activity duration, given that time constraints are less binding after work. In our sample, the average duration for shopping is $47.1 \mathrm{~min}$; however, the value is $48.4 \mathrm{~min}$ for those on work-to-home journeys and $36.3 \mathrm{~min}$ for those on home-to-work journeys. As for family/personal/other activities, the average duration is $53.5 \mathrm{~min}$, and the values are 58.9 for the work-to-home journeys and 49.2 for the home-to-work journeys.

Finally, the built-environment attributes have been indicated by the density and mix level of facilities within a radius of $1 \mathrm{~km}$ from the place of residence and workplace. Density level does not have a significant influence on the TTPs for the residence or workplace. The only significant spatial factor is the mix index around the workplace, with negative effects on both the shopping activity and family/personal/other activities. Thus, less travel time is invested in one time unit of these activities if the workplace area has more mixed land use, which can be understood as a greater proximity of stores to the workplace.

\section{Conclusion and discussion}

This research focused on the non-work stops in commuting trips by using the dataset of the "Daily Activity and Travel Survey of Beijing 2012". Compared with previous studies, which were mostly based on single-purpose trips, this study shows that chaining a stop to commuting trips reduces the travel time expenditure for non-work activities for commuters, which can benefit urban residents with tight time-budgets. The extra travel time for non-work stops and the trade-off between travel and activity time for non-work stops has been examined, and it varies among the different types of non-work stops. 
For policy making, lowering the extra travel time for non-work stops can be a way to increase commuters' utility and at the same time release the pressure imposed on the urban transport system by the extra travel time for those stops. Of the spatial factors that can be influenced by policies, mix level is more important than density, and the workplace plays a more important role than the residential environment for commuters according to the model estimation results. Therefore, a possible implication of this finding for planning practice is that raising the diversity rather than only the density of facilities will better fulfill commuters' needs. The workplace merits particular attention in this respect.

Generally, longer work duration reduces the time budget for commuters, and consequently decreases their travel time for non-work stops, regardless of activity types. However, the impacts of socio-demographics and trip-related attributes vary across the activity types. For example, gender difference is found only for eating out, which suggests that male commuters are inclined to travel longer for the same amount of activity time. As a constraint-related variable, timing (i.e., chaining a non-work stop to a work-home journey) negatively influences the travel time attributed to shopping and family/personal/ other activities as the larger time-window after work is used for a for longer activity duration. Commute duration (for direct trips) negatively influences extra travel time for eating-out, shopping and family/personal/other activities, because it results in a tighter time-budget for non-work activities.

Specifically, the descriptive analysis shows that almost $20 \%$ of the multi-purpose commute trips adopted a more motorized transport mode (compared with their direct counterparts) to adapt to the more complex agendas. Although the regression results show that active mode users and car users have lower travel time for each time unit of eating out and leisure activities, respectively, the variable of mode shift does not help reduce the proportional travel time for non-work activities. Thus, the hypothesis of shorter travel time due to reduced travel time and increased activity duration is rejected. Given a higher level of mobility and relaxed time constraints, the space-time prism for commuters is expanded with a larger choice set of non-work activities (Chen and Kwan 2012), and commuters may then relocate their non-work activity.

While our study is in line with previous studies on TTR (Soo et al. 2008; Susilo and Dijst 2009, 2010), it also shares with these studies the limitation that certain choice dimensions are regarded as exogenous, such as destination of the secondary destination, mode choice and the decision to engage in a secondary activity in the first place. While our study provides insight in the factors influencing the travel time in multi-purpose commute trips, it does not account for the fact that commuters may change mode, destination or activity participation in response to the explanatory factors used in this study. Adding these dimensions would be important if ones goal is to develop comprehensive forecasting models, and is seen as an important future activity.

It should be noted that this research has considered extra travel time rather than travel distance for non-work stops. Measuring travel expenditure in distance could be a useful addition to examine the assumption that individuals will locate their non-work stops farther when they have a higher mobility level and, consequently, a larger choice set. Another relevant future analysis may concern other possible choices for commuters, such as the adjustment of departure/arrival times, which has been proved to affect the stop-making propensity (Bhat 1999) and which may affect the travel times and travel time prices for chained activities.

Additionally, the influence of spatial factors in the current study focuses on the two anchors of commute trips, namely the place of residence and the workplace. However, a previous study based on a GPS dataset from 34 drivers in southeastern Michigan described 
the spatial configuration of non-work activities and found that non-work activities chained to home-to-work commutes are mainly located along commuting paths (Wang et al. 2013). Future explorations can take the attributes of home-to-work corridors into consideration rather than the two ends alone. Furthermore, the built environment in Chinese cities is deeply shaped by the institutional and economic transition. Variables such as community type, which has been widely discussed in previous studies concerning the built environment and travel behavior in China (Ma et al. 2014; Zhao and Chai 2013), could be taken into account in a future study. Lastly, additional research is required to examine whether the mode shift phenomenon is common for multi-purpose trips and whether its impact on travel time is similar in other contexts with different distributions of transport mode use.

Acknowledgements Data used in this study were collected by the research team led by Professor Yanwei Chai of Peking University. This research is sponsored by the 12th Five-year National Science Supported Planning Project of China (2012BAJ05b014). We would like to thank the Chinese Scholarship Council for providing the Ph.D. scholarship.

Open Access This article is distributed under the terms of the Creative Commons Attribution 4.0 International License (http://creativecommons.org/licenses/by/4.0/), which permits unrestricted use, distribution, and reproduction in any medium, provided you give appropriate credit to the original author(s) and the source, provide a link to the Creative Commons license, and indicate if changes were made.

\section{References}

Bedford, O.: Crossing boundaries an exploration of business socializing (Ying Chou for Guanxi) in a Chinese Society. Psychol. Women Quart. 40(2), 290-306 (2015). doi:10.1177/0361684315596161

Beijing Transport Research Center. Annual Report of Beijing Transport Development. http://www.bjtrc.org. cn/InfoCenter\%5CNewsAttach\%5C2012\%E5\%B9\%B4\%E5\%8C\%97\%E4\%BA\%AC\%E4\%BA\%A4\% E9\%80\%9A\%E5\%8F\%91\%E5\%B1\%95\%E5\%B9\%B4\%E6\%8A\%A5_20140303114927894.pdf (2013). Accessed 30 July 2014

Bhat, C.R.: A generalized multiple durations proportional hazard model with an application to activity behavior during the evening work-to-home commute. Transp. Res. Part B Methodol. 30, 465-480 (1996a)

Bhat, C.R.: A hazard-based duration model of shopping activity with nonparametric baseline specification and nonparametric control for unobserved heterogeneity. Transp. Res. Part B Methodol. 30, 189-207 (1996b)

Bhat, C.R.: Work travel mode choice and number of non-work commute stops. Transp. Res. Part B Methodol. 31, 41-54 (1997)

Bhat, C.R.: An analysis of evening commute stop-making behavior using repeated choice observations from a multi-day survey. Transp. Res. Part B Methodol. 33, 495-510 (1999)

Bhat, C.R., Sardesai, R.: The impact of stop-making and travel time reliability on commute mode choice. Transp. Res. Part B Methodol. 40, 709-730 (2006)

Brunow, S., Gründer, M.: The impact of activity chaining on the duration of daily activities. Transportation 40, 981-1001 (2013)

Cao, X., Mokhtarian, P.L., Handy, S.L.: Differentiating the influence of accessibility, attitudes, and demographics on stop participation and frequency during the evening commute. Environ. Plan. 35, 431-442 (2008)

Cao, X.J., Mokhtarian, P.L., Handy, S.L.: The relationship between the built environment and nonwork travel: a case study of Northern California. Transp. Res. Part A Policy Pract. 43(5), 548-559 (2009)

Cervero, R., Wu, K.L.: Sub-centring and commuting: evidence from the San Francisco bay area, 1980-90. Urban Stud. 35, 1059-1076 (1998)

Chai, Y.: Space-Time behavior research in China: recent development and future prospect: Space-Time integration in geography and GIScience. Ann. Assoc. Am. Geogr. 103, 1093-1099 (2013)

Chen, C., Mokhtarian, P.L.: Tradeoffs between time allocations to maintenance activities/travel and discretionary activities/travel. Transportation 33, 223-240 (2006) 
Chen, X., Kwan, M.: Choice set formation with multiple flexible activities under space-time constraints. Int. J. Geogr. Inf. Sci. 26, 941-961 (2012)

Currie, G., Delbosc, A.: Exploring the trip chaining behaviour of public transport users in Melbourne. Transp. Policy 18, 204-210 (2011)

Dijst, M.: Two-earner families and their action spaces: a case study of two dutch communities. GeoJournal 48, 195-206 (1999)

Dijst, M., de Jong, T., van Eck, J.R.: Opportunities for transport mode change: an exploration of a disaggregated approach. Environ. Plan. 29, 413-430 (2002)

Dijst, M., Vidakovic, V.: Travel time ratio: the key factor of spatial reach. Transportation 27, 179-199 (2000)

Farber, S., Páez, A., Mercado, R.G., Roorda, M., Morency, C.: A time-use investigation of shopping participation in three Canadian cities: is there evidence of social exclusion? Transportation 38(1), 17-44 (2011)

Frank, L.D., Andresen, M.A., Schmid, T.L.: Obesity relationships with community design, physical activity, and time spent in cars. Am. J. Prev. Med. 27, 87-96 (2004)

Golob, T.F., Bradley, M.A., Polak, J.M.: Travel and Activity Participation as Influenced by Car Availability and Use, WP-286. The University of California Transportation Center, Berkeley (1995)

Hägerstrand, T.: What about people in regional science? Pap. Reg. Sci. 24, 7-24 (1970)

Hanson, S.: The importance of the multi-purpose journey to work in urban travel behavior. Transportation $\mathbf{9}$, 229-248 (1980)

Hensher, D.A., Reyes, A.J.: Trip chaining as a barrier to the propensity to use public transport. Transportation 27, 341-361 (2000)

Horner, M.W.: Spatial dimensions of urban commuting: a review of major issues and their implications for future geographic research. Prof. Geogr. 56, 160-173 (2004)

Islam, M.T., Habib, K.M.N.: Unraveling the relationship between trip chaining and mode choice: evidence from a multi-week travel diary. Transp. Plan. Technol. 35, 409-426 (2012)

Kitamura, R. Time Use: Workshop Report. In: In Perpetual Motion: Travel Behavior Research Opportunities and Application Challenges. Oxford, Pergamon (2002)

Kitamura, R., Chen, C., Narayanan, R.: Traveler destination choice behavior: effects of time of day, activity duration, and home location. Transp. Res. Rec. 1645, 76-81 (1998)

Kondo, K., Kitamura, R.: Time-space constraints and the formation of trip chains. Reg. Sci. Urban Econ. 17, 49-65 (1987)

Levinson, D., Kumar, A.: Activity, travel, and the allocation of time. J. Am. Plan. Assoc. 61, 458-470 (1995)

Long, Y., Liu, X.: Automated identification and characterization of parcels (AICP) with OpenStreetMap and Points of Interest. arXiv Preprint arXiv:1311.6165

Ma, J., Mitchell, G., Heppenstall, A.: Daily travel behaviour in Beijing, China: an analysis of workers' trip chains, and the role of socio-demographics and urban form. Habitat Int. 43, 263-273 (2014)

McGuckin, N., Murakami, E.: Examining trip-chaining behavior: comparison of travel by men and women. Transp. Res. Rec. 1693, 79-85 (1999)

McGuckin, N., Zmud, J., Nakamoto, Y.: Trip-chaining trends in the United States: understanding travel behavior for policy making. Transp. Res. Rec. 1917, 199-204 (2005)

Neutens, T., Schwanen, T., Witlox, F.: The prism of everyday life: towards a new research agenda for time geography. Transp. Rev. 31, 25-47 (2011)

Nishii, K., Kondo, K.: Trip linkages of urban railway commuters under time-space constraints: some empirical observations. Transp. Res. Part B Methodol. 26, 33-44 (1992)

Portoghese, A., Spissu, E., Bhat, C.R., Eluru, N., Meloni, I.: A copula-based joint model of commute mode choice and number of non-work stops during the commute. Int. J. Transp. Econ. 38, 337-362 (2011)

Schwanen, T., Dijst, M.: Travel-time ratios for visits to the workplace: the relationship between commuting time and work duration. Transp. Res. Part A Policy Pract. 36, 573-592 (2002)

Schwanen, T., Dijst, M., Dieleman, F.M.: A microlevel analysis of residential context and travel time. Environ. Plan. A 34(8), 1487-1507 (2002)

Soo, J., Ettema, D., Ottens, H.F.L.: Analysis of travel time in multiple-purpose trips. Transp. Res. Rec. 2082, 56-62 (2008)

Strathman, J.G., Dueker, K.J., Davis, J.S.: Effects of household structure and selected travel characteristics on trip chaining. Transportation 21, 23-45 (1994)

Sultana, S., Weber, J.: The Nature of Urban Growth and the Commuting Transition: endless Sprawl or a Growth Wave? Urban Stud. 51, 544-576 (2014)

Susilo, Y.O., Dijst, M.: Behavioural decisions of travel-time ratios for work, maintenance and leisure activities in the Netherlands. Transp. Plan. Technol. 33, 19-34 (2010) 
Susilo, Y.O., Dijst, M.: How far is too far?: travel time ratios for activity participation in the Netherlands. Transp. Res. Rec. 2134, 89-98 (2009)

Susilo, Y.O., Kitamura, R.: Structural changes in commuters' daily travel: the case of auto and transit commuters in the Osaka metropolitan area of Japan, 1980-2000. Transp. Res. Part A Policy Pract. 42, 95-115 (2008)

Tarigan, T., Fujii, S., Kitamura, R.: Intrapersonal variability in leisure activity-travel patterns: the case of one-worker and two-worker households. Transp. Lett. 4(1), 1-13 (2012). doi:10.3328/TL.2012.04.01. $1-13$

Van Acker, V., Witlox, F.: Commuting trips within tours: how is commuting related to land use? Transportation 38, 465-486 (2011)

Walle, S.V., Steenberghen, T.: Space and time related determinants of public transport use in trip chains. Transp. Res. Part A Policy Pract. 40, 151-162 (2006)

Wang, X., Grengs, J., Kostyniuk, L.: Visualizing travel patterns with a GPS dataset: how commuting routes influence non-work travel behavior. J. Urban Technol. 20, 105-125 (2013)

Yang, M., Wang, W., Chen, X., Wan, T., Xu, R.: Empirical analysis of commute trip chaining case study of Shangyu, China. Transp. Res. Rec. 2038, 139-147 (2007)

Ye, X., Pendyala, R.M., Gottardi, G.: An exploration of the relationship between mode choice and complexity of trip chaining patterns. Transp. Res. Part B Methodol. 41, 96-113 (2007)

Zhao, Y., Chai, Y.: Residents' activity-travel behavior variation by communities in Beijing, China. Chin. Geogr. Sci. 23, 492-505 (2013)

Zidan Mao is Ph.D student in the Department of Human Geography and Spatial Planning of Utrecht University. Her research includes the commute trip making, modality styles of commuters, and how commute behaviors influence individuals' daily life practices.

Dick Ettema is associate professor in the Department of Human Geography and Spatial Planning of Utrecht University. His research interests include travel decision making and behavior change, time use and activity pattern analysis, and the influence of the built and social environment on well-being, physical activity and active travel.

Martin Dijst is professor in the Department of Human Geography and Spatial Planning of Utrecht University. His work covers transportation studies, land use planning and Information and Communication Technologies, climate change and healthy cities. 